\title{
How useful are prescribing indicators based on the DU90\% method to distinguish the quality of prescribing between pharmacotherapy audit meetings with different levels of functioning?
}

\author{
Martina Teichert • Angelie van der Aalst • \\ Hans de Wit • Marcel Stroo • Peter A. G. M. De Smet
}

Received: 1 May 2007 / Accepted: 29 July 2007 / Published online: 2 October 2007

(C) Springer-Verlag 2007

\begin{abstract}
Objectives The objective of the study was to assess the association between the quality of drug prescribing based on three indicator types derived from the DU90\% method and different levels of functioning in pharmacotherapy audit meetings (PTAMs).

Materials and methods The level of functioning in PTAMs in 2004 was assessed by a standard questionnaire. Data on prescriptions in 2004 by the GPs participating in the included PTAMs were extracted from the database of the Foundation for Pharmaceutical Statistics. Three types of DU90\% indicators were computed for the seven mostly prescribed drug classes. With univariate and multivariate analyses of variance, differences in the results of three types of indicators for each of the seven drug classes were assessed according to the levels of PTAMs.

Results For 84 PTAMs with varying levels of functioning, we found no association between the level of PTAM and the quality of prescribing for any of the indicators within the seven drug classes. In general, results gained of all PTAMs seemed to be high in quality for the aspects measured.
\end{abstract}

M. Teichert $(\bowtie) \cdot$ P. A. G. M. De Smet

Scientific Institute Dutch Pharmacists,

Alexanderstraat 11,

2514 JL The Hague, The Netherlands

e-mail: m.teichert@winap.nl

A. van der Aalst $\cdot$ M. Stroo

The Dutch Institute for Proper Use of Medicines,

Utrecht, The Netherlands

H. de Wit

Foundation for Pharmaceutical Statistics,

The Hague, The Netherlands
Conclusions It is difficult to define indicators based on the DU90\% method, which can readily distinguish differences in the quality of drug prescribing between PTAMs with different levels of functioning. Indicators for prescribing should specifically meet relevant items in the quality of prescribing for certain drug classes. Items for classification of PTAM levels may need some reconsideration.

Keywords Prescribing indicators · Pharmacotherapy audit meetings · Drug use $90 \%$ method

\section{Introduction}

In The Netherlands, pharmacotherapy audit meetings (PTAMs) are established since 1990. These are local meetings of GPs and community pharmacists to make agreements on pharmacotherapy based on national guidelines and with regard to the costs of medicines to improve prescribing and dispensing of drugs. Depending on the local character, these groups differ concerning participating number of GPs and pharmacists, frequency and duration of the meetings, choice and the way of discussing topics and the adherence to agreements made in the daily practice of prescribing. By this, the nowadays more than 800 PTAMs in the Netherlands differ in the quality of functioning. It is to be expected that PTAMs with strict rules, which meet more regularly and reach obligatory agreements, will prescribe and dispense drugs more efficiently with regards to quality and costs. Research of this association, however, is still scarce. In The Netherlands, there were two studies with different results. Muijrers et al. [1] did not find any association between the quality of prescribing and the 
quality of PTAMs. Florentinus et al. [2], however, showed that PTAMs functioning on a higher level of cooperation were less susceptible to marketing influences to prescribe newly introduced drugs, and therefore, showed a higher quality in prescribing. Regarding these conflicting results, we decided to investigate the association between the quality of PTAMs and the quality of drug prescribing, taking into account a number of lessons learnt from the earlier studies. First, the levels of PTAMs in one of the earlier studies had been judged by self-made questionnaires [3]. We made use of the routine assessment of the quality of functioning in PTAMs from 2004 performed annually by The Dutch Institute for the Proper use of Medicines (DGV) since 2000 on behalf of the Dutch Ministry of Health $[4,5]$. Second, for the judgement of the quality of prescribing, we used the drug utilization $90 \%$ (DU90\%) method [6]. In Sweden, this method has been introduced as an inexpensive, flexible and simple manner to assess the quality of drug prescribing which is recommended for that aim by the Swedish Medical Quality Council. The DU90\% method focuses on $90 \%$ of the delivered drug volume and supplies three general quality indicators for prescribing [7]. Third, we applied the DU90\% to each of the seven mostly prescribed groups of drugs where we expected the influence of PTAMs to become most obvious. Fourth, we restricted the DU90\% method to first prescriptions, and by this, excluded repeat prescribing, as changes in prescription behaviour become better visible in new than in existing drug regimens [8]. Fifth, for the quality of prescribing, we made use of dispensing data of pharmacies collected by the Foundation of Pharmaceutical Statistics (SFK). Concerning drug exposure, pharmacy databases are superior to prescribing data reflecting the medication actually dispensed [9]. Dispensing data have proven to correlate well with patient questionnaires on actual drug intake for chronically used drugs [10]. In this cross-sectional population-based study, we investigated the association between the quality of functioning in PTAMs, categorised into four levels by annual quality assessments, and the quality of prescribing, measured by the DU90\% method with first dispensing of participating GPs for three indicator types within the seven mostly prescribed groups of drugs based on dispensing data.

\section{Materials and methods}

Inclusion of PTAMs

In the end of 2005,257 of the more than 800 PTAMs were asked to join the study. In stratified selection, 50 PTAMs for each of the four levels (based on the quality assessment of DGV in 2004) and 57 PTAMs with no level available were invited. As it is possible that more than one community pharmacy participates in a PTAM, a total of 387 pharmacies had to be asked for permission to use their data in this study. Pharmacists further had to identify the GPs participating in their PTAM in 2004 by the anonymous codes from their computer systems. For this purpose, an online accessible web form was created. A third precondition for PTAMs to join the study was that pharmacies had delivered complete dispensing data to SFK from the year 2004 and from the second half of 2003 to distinguish first prescriptions from repeat prescribing. The SFK routinely collects dispensing data from more than $90 \%$ of the total of about 1,800 community pharmacies in The Netherlands. These data include detailed information on drugs dispensed such as the codes from the anatomic therapeutic chemical (ATC) system [11] and cost price. Dispensings are linked to the patients having been prescribed the drug in question. Patients are identified by an anonymous code, gender and year of birth, being the only information of the patient himself. Furthermore, for each dispensing, prescribers can be identified by speciality, and GPs further have an anonymous code.

Levels for the quality of functioning of PTAMs

Levels of functioning were assigned by a standard questionnaire developed by DGV for annual quality assessments $[4,5]$. Six objective criteria were judged by an expert panel to be most important for cooperation within PTAMs such as the frequency and duration of the meetings, a jointly preparation of GPs and pharmacists, coming to agreements and checking the implementation of agreements in prescribing practice (Table 1). These questionnaires were sent to a GP and a pharmacist as the declared contacts of each PTAM. The results collected for six criteria in 2004 were used to scale all PTAMs into one of the four different levels of cooperation by an investigator of DGV (Table 2).

Table 1 Six domains for quality assessment of the PTAMs

Parameters

Number of FTO meetings

Median duration of FTO meetings

Joined preparation of GP and pharmacist (yes or no)

Use of feedback information by prescription data concerning prescribed volume, costs/DDD and preferences in drug choice per GP (yes or no)

Written down agreements on drug choices (yes or no)

Routine check of adherence to the agreements made with prescription data (yes or no) 
Table 2 Four levels for the quality of functioning of PTAMs

\begin{tabular}{ll}
\hline Level & Description \\
\hline Level 1 & No structured meetings \\
Level 2 & $\begin{array}{c}\text { Frequent meetings without concrete decisions } \\
\text { Level 3 }\end{array}$ \\
& $\begin{array}{c}\text { Frequent meetings with concrete decisions, supported by } \\
\text { use of feedback information with prescription data, but } \\
\text { without evaluation of these decisions }\end{array}$ \\
Level 4 & $\begin{array}{c}\text { Frequent meetings with concrete decisions and } \\
\text { evaluation of these decisions }\end{array}$ \\
\hline
\end{tabular}

Indicators for the quality of prescribing based on an adjusted DU90\% method

The DU90\% method was applied to the seven groups of drugs that had more than 4 million prescriptions in 2004: HMGCoA reductase inhibitors, drugs for acid-related disorders, antibacterials for systemic use, antidepressants, benzodiazepine derivatives, drugs for obstructive airway diseases and oral blood-glucose-lowering drugs (Table 3). For these groups, only prescriptions of the GPs participating in the included PTAMs were selected in 2004. From these, only first dispensings were derived from the

Table 3 Selection of drugs from the seven groups, classification of guideline drugs and non-guideline drugs mostly encountered

\begin{tabular}{|c|c|c|c|c|}
\hline Group of drugs & ATC & & Guideline drugs & $\begin{array}{l}\text { Mostly encountered non- } \\
\text { guideline drugs in our } \\
\text { study population }\end{array}$ \\
\hline $\begin{array}{l}\text { HMG CoA } \\
\text { reductase inhibitors }\end{array}$ & C10AA & C10AA01, C10AA03 & Simvastatin, Pravastatin & $\begin{array}{l}\text { Fluvastatin, } \\
\text { Rosuvastatin, } \\
\text { Atorvastatin }\end{array}$ \\
\hline $\begin{array}{l}\text { Drugs for acid-related } \\
\text { diseases }^{\mathrm{a}}\end{array}$ & A02 & A02A, A02BA & $\begin{array}{l}\text { Antacids, H2-receptor } \\
\text { antagonists }\end{array}$ & Proton pump inhibitors \\
\hline \multirow{5}{*}{$\begin{array}{l}\text { Antibacterials for } \\
\text { systemic use }\end{array}$} & \multirow[t]{5}{*}{ J01 } & J01A, J01B & Tetracyclines, Amfenicoles & \multirow{5}{*}{$\begin{array}{l}\text { Quinolone antibacterials } \\
\text { Amoxiciline and enzyme } \\
\text { inhibitor } \\
\text { Cefalosporins }\end{array}$} \\
\hline & & J01C except J01CR02 & $\begin{array}{l}\text { Beta-lactam antibacterials except } \\
\text { amoxicilline and enzyme } \\
\text { inhibitor }\end{array}$ & \\
\hline & & $\mathrm{J} 01 \mathrm{E}$ & Sulfonamids and Trimethoprim & \\
\hline & & $\mathrm{J} 01 \mathrm{~F}$ & $\begin{array}{l}\text { Macrolides, lincosamides, } \\
\text { streptogramins }\end{array}$ & \\
\hline & & $\mathrm{J} 01 \mathrm{X}$ & $\begin{array}{l}\text { Other antibacterials (e.g. Fusidic } \\
\text { acid) }\end{array}$ & \\
\hline \multirow[t]{3}{*}{ Antidepressants } & \multirow[t]{3}{*}{ N06A } & N06AA09, N06AA02 & Amitryptiline, Imipramine & $\begin{array}{l}\text { Maprotiline, } \\
\text { Clomipramine, } \\
\text { Fluoxetine }\end{array}$ \\
\hline & & N06AA10, N06AB08 & Nortriptyline, Fluvoxamine & Citalopram, Trazodone, \\
\hline & & N06AB05, N06AB06 & Paroxetine, Sertraline & Venlafaxine, Mirtazapin \\
\hline \multirow{3}{*}{$\begin{array}{l}\text { Benzodiazepine } \\
\text { derivatives and } \\
\text { related drugs }{ }^{\mathrm{b}}\end{array}$} & N05BA & N05CD07, N05CF02 & Temazepam, Zolpidem & \multirow{3}{*}{$\begin{array}{l}\text { Triazolam, } \\
\text { Lormetazepam, } \\
\text { Flunitrazepam, } \\
\text { Loprazolam, } \\
\text { Clobazam, } \\
\text { Bromazepam, } \\
\text { Lorazepam, Oxazepam, } \\
\text { Chloordiazepoxide, } \\
\text { Alprazolam, Zopiclone }\end{array}$} \\
\hline & N05CD & N05BA01 & Diazepam & \\
\hline & N05CF & & & \\
\hline \multirow[t]{3}{*}{$\begin{array}{l}\text { Drugs for obstructive } \\
\text { airway diseases }\end{array}$} & \multirow[t]{3}{*}{$\mathrm{R} 03$} & $\mathrm{R} 03 \mathrm{AC}$ & $\begin{array}{l}\text { Selective beta-2-adrenoreceptor } \\
\text { agonists }\end{array}$ & \multirow{3}{*}{$\begin{array}{l}\text { Adrenergis for systemic } \\
\text { use, Theophylline, } \\
\text { Montelukast }\end{array}$} \\
\hline & & R03BA, R03BB & Glucocorticoids, Anticholinergics & \\
\hline & & $\mathrm{R} 03 \mathrm{BC} 01$ & Cromoglicic acid & \\
\hline $\begin{array}{l}\text { Oral blood glucose } \\
\text { lowering drugs }\end{array}$ & $\mathrm{A} 10 \mathrm{~B}$ & $\begin{array}{l}\text { A10BB } \\
\text { A10BA02, A10BF01 }\end{array}$ & $\begin{array}{l}\text { Sulfonamides, urea derivatives } \\
\text { Metformin, Acarbose }\end{array}$ & $\begin{array}{l}\text { Repaglinide, } \\
\text { Thiazolidinediones }\end{array}$ \\
\hline
\end{tabular}

${ }^{a}$ Drugs of first choice according to the corresponding NHG standard were only suitable for patients without use of NSAIDs. Therefore, for the index of adherence of the antacids, special DU90\% segments had to be calculated for all PTAMs, with the additional postulation that only first deliveries of selected GPs were included for those patients who had not had a prescription of a NSAID in the preceding 4 months.

${ }^{\mathrm{b}}$ The valid NHG standard for hypnotics dated from 1992 and was quite obsolete. To better meet the actual standards and recommendations, we labelled the guideline drugs, recommended by another commonly used standard [23]. 
SFK database. 'A first dispensing' was defined as the delivery of a drug to a certain patient who, in the preceding half year, had not had a similar prescription of the same substance (on fifth ATC level and thereby regardless of dosage, dosage form, pack size and brand) [11]. For each FTO group, the first dispensings of the participating GPs expressed as the number of defined daily doses (DDDs) per ATC-5 code were calculated separately within the seven medication groups. Within each of the seven groups of drugs and for each PTAM, the substances were ranked by descending volume of DDDs to estimate DU90\% segments for drug utilisation as described earlier by Bergman et al. [7]. The DU90\% method focuses on $90 \%$ of the delivered drug volume. The borderline of $90 \%$ is an arbitrary but useful choice to study the bulk of prescribing while still allowing some leeway for individual variation due to special patient conditions. The DU90\% method supplies three general quality indicators for prescribing [7]. One indicator type addresses the number of drugs within the DU90\% segment (defined as substance of the same ATC code, fifth level). The second indicator is based on the percentage of drugs according to accepted guidelines within the DU90\% segment. The third indicator measures economic aspects by the relationship between the costs per DDD in the DU90\% segment and the costs per DDD in the remaining segment.

From this, we deduced the following three indicators to assess the quality of prescribing:

1. Prescribing according to ATC

2. Prescribing according to guidelines

3. Cost-effective prescribing

1. Prescribing according to ATC

Within the DU90\% segments of all seven groups of drugs, it was determined how many substances (fifth ATC level) accounted for the DU90\% segment. Physicians are expected to manage prescribing by restricting it to a limited number of drugs. High quality of prescribing is then associated with the use of a relatively limited number of pharmaceutical products within a drug group [6]. PTAMs are expected to come to agreements on the drugs preferred for treatment of certain diseases. As PTAMs functioning on a higher level should be more able to make specific choices and follow these, we expected the number of drugs within a certain group of drugs to decrease with higher levels of PTAMs.

2. Prescribing according to guidelines

The national practice guidelines for GPs provide evidence-based recommendations for drugs of first choice for average patients with the indication in question. For each group, drugs were classified as permitted or not recommended by the guidelines. Classification was done on the basis of the Dutch Practice Guidelines for GPs (NHG- standards) valid in 2004 (the Dutch Standards have been described elsewhere [12]). We made use of the online accessible updates on the web site of the Dutch organization of GPs [13-19]. The particular choices made are listed in Table 3. Consecutively, the number of DDDs of the guideline drugs was related to the whole number of DDDs in the DU90\% segment [6]. Better functioning PTAMs are more likely to come to binding agreements on using drugs recommended by the guidelines and not for instance advocated by industrial marketing. We expected the index of adherence for each group of drugs within the DU90\% segment to increase with higher levels of PTAMs.

\section{Cost-effective prescribing}

For each ATC code, the actual cost per DDD as cost price for the pharmacy were recorded at the moment of dispensing (without value-added tax and regardless of the amount of reimbursement per prescription or discount). Per PTAM, the mean cost/DDD were estimated for each DU90\% segment and for the remaining 10\% segment of the seven drug groups. Consecutively, the relationship of the cost/DDD in the remaining $10 \%$ segment and the DU90\% was calculated (cost/DDD of remaining $10 \%$ segment divided by cost/DDD of DU90\% segment) [6]. When coming to agreements of drugs to be used preferably, PTAMs are also expected to take costs into account. Comparison between the median costs/DDD within the remaining segment of scarcely prescribed drugs and the DU90\% segment for each of the seven drug groups is likely to elucidate in how far the drug choices were also related to costs. As PTAMs on a higher level were likely to succeed better in consistent cost-effective choices, we expected the indicator to be increased with higher levels of PTAMs.

\section{Analyses}

Within all three indicator types, mean results (plus standard deviation) for the seven groups of drugs were calculated for each PTAM. With univariate and multivariate analyses of variance (MANOVA), variation between the levels of PTAMs was checked for all indicators of the seven drug groups within all three types of indicators. With MANOVA, analyses could be performed for all seven drug groups within one type of indicator simultaneously, adjusting for the fact that within a type of indicator, the same PTAMs were repeatedly measured for outcome of the seven drug classes. Further, we adjusted for the number of GPs per PTAM in categories from 1 to $10 \mathrm{GPs}, 11$ to $20 \mathrm{GPs}, 21$ to $30 \mathrm{GPs}$ and more than $30 \mathrm{GPs}$ per PTAM. All analyses were done with SPSS 12.1 for Windows (SPSS, Chicago, IL, USA). 
Prescribing according to ATC for different groups of drugs in relation with levels of PTAM and corrected for number of GPs

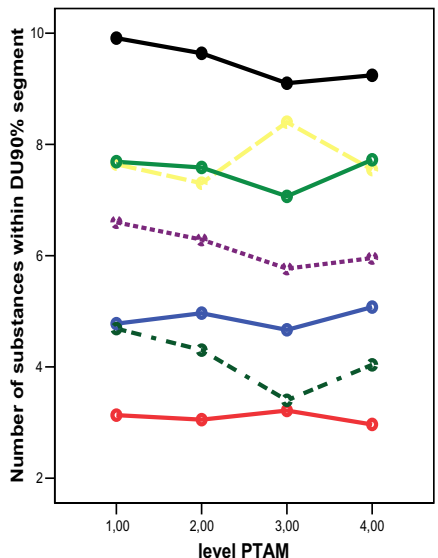

Legend:
Prescribing according to guidelines for different groups of drugs in relation with levels of PTAMs and corrected for number of GPs

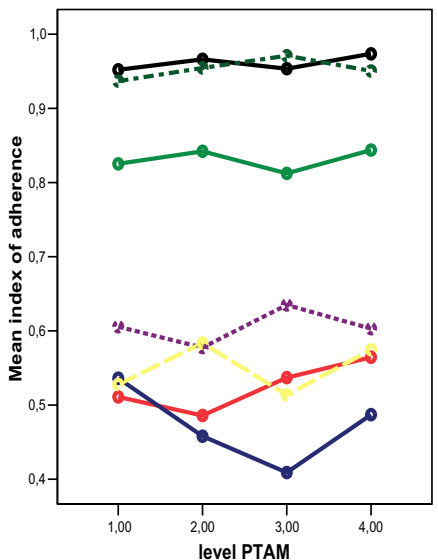

Cost-effective prescribing for different groups of drugs in relation with levels of PTAMs and corrected for number of GPs

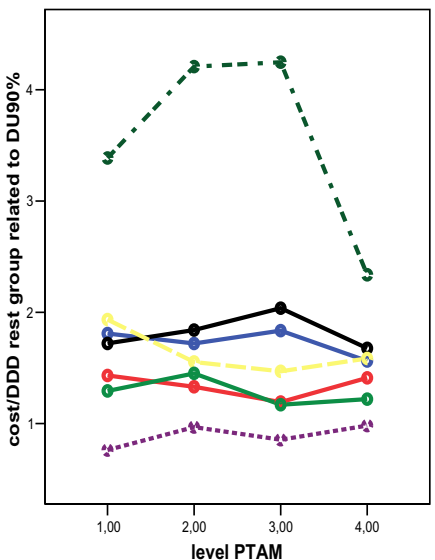

$$
\begin{aligned}
& \text { HMGCoA reducatse inhibitors } \\
& \text { - Acid related disor ders } \\
& \text { - Antibacterials (systemic) } \\
& \text { Benzodiazepines } \\
& \text { - Antidepressants } \\
& \text { - Obstructive airway diseases }
\end{aligned}
$$

Fig. 1 Prescribing according to ATC, according to guidelines and cost-effective prescribing for different groups of drugs and all levels of PTAMs

\section{Results}

\section{Participating PTAMs}

From the 387 pharmacies belonging to 257 PTAMs invited for participation in this study, 182 pharmacies (corresponding to 122 PTAMs) gave permission to use their data (47\% response). One hundred twenty-two pharmacists belonging to totally 96 PTAMs identified their participating GPs (67\% of responding pharmacists). Among these were 11 PTAMs which not had permitted the use of their data. One pharmacy had switched from computer system in 2005 so that the codes for the GPs when filling the web form did not correspond any longer with the data delivered in 2004. Therefore, the data of the corresponding PTAM could not be used. For our study, data of 102 pharmacies were available belonging to 84 PTAMs (26\% of the contacted pharmacies and $33 \%$ of the invited PTAMs). The distribution of these PTAMs within the different levels is shown in Table 4. The number of participating GPs did not differ significantly between these groups.

Results of the three indicators

\section{Prescribing according to ATC}

The mean number of drugs within the DU90\% segment for the seven groups of drugs ranged from of 3.1 for the HMG CoA reductase inhibitors to 9.6 for the antibacterials for systemic use. Within a certain group of drugs, however, the number of drugs was quite similar for all levels of
PTAMs (Fig. 1). MANOVA could not detect any differences in the number of DU90\% drugs for the levels of PTAMs $(p=0.144)$. The number of GPs had no significant impact on the number of DU90\% drugs $(p=0.884)$.

2. Prescribing according to guidelines

The index of adherence to guidelines for the seven groups of drugs on average ranged from $48 \%$ for the drugs for acid related disorders to $96 \%$ for the antibacterials for systemic use. Within a certain group of drugs, however, the index of adherence was quite similar for all levels of PTAMs (Fig. 1). MANOVA could not detect any differences in the index of adherence for the four levels of PTAMs $(p=0.836)$. The number of GPs had no significant impact on the index of adherence $(p=0.963)$.

\section{Cost-effective prescribing}

The cost per DDD within the DU90\% segment on average ranged from $0.14 € / D D D$ for the benzodiazepine derivatives up to $0.99 € / \mathrm{DDD}$ for the antibacterials for systemic use. In the remaining segment, the cost /DDD varied from $0.22 € / \mathrm{DDD}$ for the benzodiazepine derivatives

Table 4 Numbers of PTAMs and GPs per level of PTAM

\begin{tabular}{lll}
\hline Level of PTAMs & Number of PTAMs $(\%)$ & Number of GPs (SD) \\
\hline Not classified & $7(8)$ & $6.6(2.2)$ \\
1 & $21(25)$ & $10.4(7.0)$ \\
2 & $23(27)$ & $8.1(3.5)$ \\
3 & $15(18)$ & $9.3(6.7)$ \\
4 & $18(27)$ & $10.9(5.5)$ \\
Total & $84(100)$ & \\
\hline
\end{tabular}


up to $1.62 € / \mathrm{DDD}$ for the antibacterials for systemic use. The relationship between the cost/DDD of the rest segment and the cost/DDD of the DU90\% segment was taken as indicator. A high result indicated a large difference in costs for the drugs seldom dispensed compared to those responsible for $90 \%$ of dispensed volume. Except for the group of the oral blood-glucose-lowering drugs (ratio 3.6), the groups had mean ratios between 0.9 and 1.8 for the costs/DDD in the remaining segment divided by the costs/ DDD for the DU90\% segment.

MANOVA could not detect any differences in cost effectiveness for the four levels of PTAMs $(p=0.636$; Fig. 1). The number of GPs had no significant impact on the indicator for cost effectiveness $(p=0.744)$.

\section{Discussion}

In this cross-sectional study, we found no association between the level of functioning of PTAMs and the quality of prescribing for any drug group within the three indicator types chosen. Although we made several improvements in the choice of the prescribing indicators and the quality assessment of PTAMs compared to earlier studies, our findings were similar to those of Muijrers et al. [1]. However, these results are counterintuitive to the prevailing and general opinion that it makes sense to have wellorganised PTAMs. We therefore critically evaluated our methods and results to see if we could come up with a plausible explanation for our findings. First of all, we looked at the selected prescribing indicators. In Sweden, the selected DU90\% method had been used successfully to assess and distinguish the quality between primary healthcare centres [7]. In our study, however, differences between the levels of PTAMs turned out to be less substantial than those between the Swedish healthcare centres [6]. Apparently, the quality of prescribing concerning a restricted number of drugs, a choice concerning the guidelines and the cost efficiency in The Netherlands, is generally high and may approach an optimum in daily practice. This is quite obvious for the index of adherence found for the oral blood-glucose-lowering drugs and the antibacterials for systemic use. In acid-related disorders, however, the guideline acceptance seemed to be generally low, possibly due to considerations in daily practice that overall do not match with the recommendation in the standards. For the prescribing according to ATC, there is no general agreement on the lowest number possible within one drug class still warranting a desired level of prescribing quality for the individual patient. However, the low numbers of drugs within HMGCoA inhibitors, oral blood-glucose-lowering agents and agents for acid-related disorders found in our study seem to represent an overall high quality of prescribing. The cost-effectiveness was also overall high for oral blood-glucose-lowering drugs which was the only drug class with substantial differences in costs/DDDs. Possibly due to high quality of prescribing for these three aspects in general, our three indicator types were not suitable to detect differences in the quality of prescribing for different levels of functioning in PTAMs. To distinguish the quality of drug prescribing in our country, indicators should be more sophisticated and address specific aspects in the daily practice of good prescribing within each drug class [9]. For instance, with antidepressants, the suitable duration of treatment may be more relevant for good prescribing than using the first drug choice from the guidelines [20]. In diabetes, the supply of HMGCoA reductase inhibitors as co-medication may be more important than the number of different oral blood-glucoselowering drugs [21]. For obstructive airway diseases, co-prescribing and concordance with corticosteroids is more decisive for patients prognosis than choices according to guidelines [22]. Second, in using the DU90\% method, the estimation of segments may need further specification, especially for the aspect of cost effectiveness. As DDDs in general are not always equipotent and may not, in all cases, represent the prescribed daily practice, the costs of the DU90\% may be misclassified. For atorvastatin for instance, normally two DDDs are used as daily dosage. Based on the DDD classification, the DU90\% volume in our study overestimated the volume of HMGCoA reductase inhibitors and underestimated the costs per effective DDD.

We also looked at the tool for measuring the quality of PTAM. This tool was based on criteria that had been valued as crucial and suitable by an expert panel and had been proven to be applicable in practice [4]. However, other criteria than the selected ones might be more decisive for public health. An example of an additional criterion is the one Florentinus et al. [2] found to be related with the quality of prescribing, namely to agree on one representative within a PTAM to receive the visitors of the pharmaceutical industry. Evaluation of the classification of PTAM levels of 2004 showed that only half of the PTAMs, being able to make and to evaluate decisions, actually were classified as the highest level. The main reasons for a lower classification were due to the lack of meeting the criteria on the number and duration of meetings. However, PTAMs meeting less than five times per year and being in conference for less than $1.5 \mathrm{~h}$ might be quite able to make and fulfil agreements on high quality of prescribing. Thus, the functioning of PTAMs may have been underestimated in our study, which may explain that also PTAMs of lower levels were able to reach high scores in the quality of prescribing.

Another possible explanation could be selection bias caused by the voluntary participation in our study which 
was quite low. In 2004, there were in total 824 PTAMs in The Netherlands, of which, $14 \%$ were in level 1, $43 \%$ were in level 2, 20\% were in level 3 and 23\% were in the highest level 4. Due to our stratified invitation of 50 groups from each level and 57 groups of no classified level, we managed to include sufficient numbers within each level. On average, PTAMs in The Netherlands had 9.6 GPs, comparable to the number of participating PTAMs in our study. Only a quarter of the pharmacists corresponding with one third of the PTAMs invited finally succeeded in participation. Possibly, by this, we included primarily those PTAMs being well organised and with a high level of cooperation regardless of the quality level assessed. The classification into the different PTAM levels might not have created substantial differentiation between participating groups, and this could be an explanation for the fact that the results of our indicators were nearly the same for the different PTAM levels.

A further limitation was our lack of information about the topics that have actually been discussed by the PTAMs in 2004 and earlier. It is possible that PTAMs made agreements on other aspects than the three indicator types chosen. Perhaps, agreements were made on the duration of treatment with antidepressants, on co-medication with HMGCoA inhibitors in patients with diabetes or on usage of new drugs, but as mentioned above, these were not measured by our three indicator types.

In conclusion, it is difficult to define indicators based on the DU90\% method that can readily distinguish differences in the quality of drug prescribing between PTAMs with different levels of functioning. Indicators have to be more sophisticated and to meet relevant aspects of the pharmacotherapy within certain drug classes. Items for classification of PTAM levels may need some reconsideration.

\section{References}

1. Muijrers PEM, Grol RPT, Sijbrandij J, Janknegt R, Knottnerus JA (2005) Differences in prescribing between general practitioners. Impact of the cooperation with pharmacists and visits from Pharmaceutical industry representatives. Fam Pract 22(6):624-630

2. Florentinus SR, van Hulten R, Kloth ME, Heerdink ER, Griens AM, Leufkens HG, Groenewegen PP (2007) The effect of pharmacotherapy audit meetings on early new drug prescribing by general practitioners. Ann Pharmacother 41(2):319-324

3. Muijrers PEM, Knottnerus JA, Sijbrandij J, Janknegt R, Grol RPTM (2004) Development and validation of guideline-based prescribing indicators as an instrument to measure the variation in the prescribing behaviour of general practitioners. Eur J Clin Pharm 60(10):739-746
4. Groot de J, Eimers M (2004) FTO-peiling 2004. Kwaliteit van farmacotherapeutisch overleg in Nederland in beeld. DGV

5. Eimers M, Groot de J, Meulepas M (2006) Benchmark voorschrijven 2006. De ontwikkeling en toepassing van prestatieindicatoren. DGV

6. Wettermark B, Pehrsson A, Jinnerot D, Bergman U (2003) Drug utilisation $90 \%$ profiles - a useful tool for quality asse ssment of prescribing in primary health care in Stockholm. Pharmacoepidemiol Drug Saf 12:499-510

7. Bergman U, Popa C, Tomson Y, Wettermark B, Einarson TR, Aberg H, Sjöqvist F (1998) Drug utilization $90 \%$ - a simple method or assessing the quality of drug prescribing. Eur J Clin Pharmacol 54:113-118

8. Stafford RS, Furberg CD, Finkelstein SN, Cockburn IM, Alehegn $\mathrm{T}$, Ma J (2004) Impact of clinical trial results on national trends in alpha-blocker prescribing, 1996-2002. JAMA 7:291(1):54-62 (Jan)

9. Hoven JL, Haaijer_Ruskamp FM, Van der STichele RH (2005) Indicators of prescribing quality in drug utilisation research: report of a European meeting (DURQUIM, 13-15 May 2004). Eur J Clin Pharmacol 60(11):831-834

10. Monster TB, Janssen WM, de Jong PE, de Jong-van den Berg LT (2002) PREVEND study group prevention of renal and vascular ENT stage disease. pharmacy data in epidemiological studies: an easy to obtain and reliable tool. Pharmacoepidemiol Drug Saf 11 (5):379-384 (Jul-Aug)

11. World Health Organization Collaborating Centre for Drug Statistics Methodology (2004) Guidelines for ATC Classification and DDD Assignment. Oslo

12. Meulenberg F, Thomas S, van der Voort H (eds) (1993) NHG standards. 5. Examples of guidelines for general practice. Dutch College of General Practitioners, Utrecht, Netherlands

13. Nederlandse Huisartsen Genootschap (1999) NHG Standaard Cholesterol, Huisarts en Wetenschap 42(9)

14. Nederlandse Huisartsen Genootschap (2003) NHG Standaard Maagklachten http://nhg.artsennet.nl, visited 11.02.06

15. Nederlandse Huisartsen Genootschap (2003) NHG Standaard Depressieve Stoornis http://nhg.artsennet.nl, visited 11.02.06

16. Nederlandse Huisartsen Genootschap (1992) NHG Standaard Slaapproblemen en slaapmiddelen. http://nhg.artsennet.nl, visited 11.02 .06

17. Nederlandse Huisartsen Genootschap (1998). NHG Standaard Astma bij kinderen. http://nhg.artsennet.nl, visited 11.02.06

18. Nederlandse Huisartsen Genootschap (2001) NHG Standaard Astma bij volwassenen. http://nhg.artsennet.nl, visited 11.02.06

19. Nederlandse Huisartsen Genootschap (1999) NHG Standaard Diabetes mellitus type 2. Huisarts en Wetenschap 42:67-84

20. Bosmans JE, Brook OH, van Hout HP, de Bruijne MC, Nieuwenhuyse H, Bouter LM, Stalman WA, van Tulder MW (2007) Cost effectiveness of a pharmacy-based coaching programme to improve adherence to antidepressants. Pharmacoeconomics 25(1):25-37

21. Rosenberg JM, Zerilli T, Nathan JP, McGuire H (2007) Use of statins and gemfibrozil in patients with type 2 diabetes mellitus and cardiovascular risk factors attending adult day health care centers: an opportunity for pharmacists. Consult Pharm 22 (1):38-44

22. Abdullah AK, Khan S (2007) Evidence-based selection of inhaled corticosteroid for treatment of chronic asthma. J Asthma 44(1): $1-12$

23. College voor Zorgverzekeringen CVZ (2004) Farmacotherapeutisch Kompas.CVZ, Naarden 2004 